\title{
Structures and macrosegregation of a 2024 aluminum alloy fabricated by direct chill casting with double cooling field
}

\author{
Cheng Zhu',2, *Zhi-hao Zhao', Qing-feng Zhu', ${ }^{1,2}$, Gao-song Wang ${ }^{1,2}$, Yu-bo Zuo², and Gao-wu Qin ${ }^{1,3}$ \\ 1. Research Center for Metallic Wires, School of Materials Science and Engineering, Northeastern University, Shenyang 110819, China \\ 2. Key Laboratory of Electromagnetic Processing of Materials, Ministry of Education, Northeastern University, Shenyang 110819, China \\ 3. Key Laboratory of Anisotropy and Texture of Materials, Ministry of Education, Northeastern University, Shenyang 110819, China
}

\begin{abstract}
Central region coarse grains and centerline segregation are common defects in aluminum ingots fabricated by direct chill (DC) casting. A double cooling field was introduced into the DC casting process to reduce these defects, whereby the external cooling was supplied by the mold and water jets, and intercooling was achieved by inserting a rod of the same alloy into the molten pool along the central axis of the ingot. Rather than forming a good metallurgical interface during solid-liquid compound casting, in the present work, the purpose of inserting the rod is to enforce internal cooling and consequently decrease the sump depth. Moreover, the insertion provides more nucleation sites with the unmolten $\alpha$-Al particles. The structure and the macrosegregation of 2024 Al alloy ingots prepared by DC casting with and without the inserts were investigated. Results show that when the inserting position is $50 \mathrm{~mm}$ above the upper edge of the graphite ring, significant grain refinement in the central region of the ingot and a reduced centerline segregation are achieved.
\end{abstract}

Keywords: aluminum alloy; direct chill casting; double cooling field; grain refinement; macrosegregation

CLC numbers: TG146.21 Document code: $\mathrm{A}$

Article ID: 1672-6421(2022)01-001-08

\section{Introduction}

Large-size aluminum alloy ingots produced by traditional direct chill (DC) casting, especially the $2 \mathrm{xxx}$ and $7 \mathrm{xxx}$ series, often have defects such as inhomogeneous structure, macrosegregation, and hot cracks ${ }^{[1-4]}$. Although adding grain refiners improves the quality of largesize ingots, it could lead to agglomeration of nucleating particles and fading effect ${ }^{[5-6]}$. In addition, physical methods, including mechanical stirring ${ }^{[7-8]}$, ultrasonic vibration ${ }^{[9]}$, and electromagnetic stirring ${ }^{[10]}$, are not easy to apply in the DC casting process because of the expensive and specific equipment requirements.

Recently, several new methods have been developed by adding intercooling in the DC casting process. For instance, an in-mold cooler with a cooling end made of highly pure graphite can be inserted into the melt to absorb and transfer the heat during the liquid or gas flow in the cooler ${ }^{[11-12]}$. Another way to enhance

\section{*Zhi=hao Zhao}

Male, born in 1976, Professor. His research interests mainly focus on the electromagnetic casting and the extrusion forming of aluminum alloys.

E-mail: zzh@epm.neu.edu.cn

Received: 2021-04-28; Accepted: 2021-08-11 intercooling is by inserting a smaller cold material of the same compositions into the melt during copper alloy DC casting ${ }^{[13]}$. This method was also studied in the squeeze casting of aluminum alloys ${ }^{[14-15]}$ and die casting of magnesium alloys ${ }^{[16]}$. However, the purpose of that method is to obtain an excellent metallurgical bonding between the insert and the melt. Our previous study found that inserting a cold $2024 \mathrm{Al}$ alloy rod into the $2024 \mathrm{Al}$ melt during mold casting can refine the grains ${ }^{[17]}$. Eskin et al. ${ }^{[18]}$ confirmed the grain refinement effect of introduction the same-alloy rod into the melt in a standard TP- 1 mold casting and achieved significant grain refinement. Therefore, it is of great use to refine grains in the DC casting process by inserting cold material into the melt.

In this study, a $2024 \mathrm{Al}$ alloy rod was inserted into the $2024 \mathrm{Al}$ alloy melt during hot-top DC casting, whose chemical compositions are $\mathrm{Al}-4.0 \mathrm{wt} . \% \mathrm{Cu}-1.6 \mathrm{wt} . \% \mathrm{Mg}$ 0.6wt.\% Mn-0.12wt.\% Fe-0.03wt.\% Si. Compared with traditional DC casting with a single cooling field (SCF), the cold $2024 \mathrm{Al}$ alloy rod provides another cooling field with its latent heat consumption while melting. The intercooling from the insert and the cooling from the mold and water jet are called a double cooling field (DCF), which are expected to decrease the 
temperature gradient from the surface to the center of the ingot and provide more nucleation sites. The solidification structures and macrosegregation of the ingots with SCF or DCF were examined, and the effects of the $2024 \mathrm{Al}$ alloy insert on the grain refinement and segregation reduction were investigated.

\section{Experimental procedure}

Commercial $2024 \mathrm{Al}$ alloy (without grain refiner) and 2024 $\mathrm{Al}$ alloy extrusion rods, as shown in Fig. 1, were used as ingot materials and inserts, respectively. The rods are $20 \mathrm{~mm}$ in diameter and 1,500 $\mathrm{mm}$ in length. Their surfaces were polished by 400 grit silicon carbide papers, treated by alkaline cleaning and acid pickling. The $2024 \mathrm{Al}$ rods consist of typical fibrous

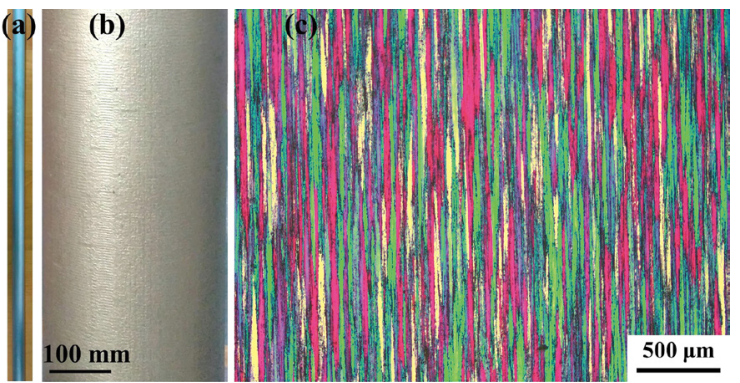

Fig. 1: Images of $2024 \mathrm{Al}$ rod (a), ingot (b), and OM images of 2024 Al rod (c)
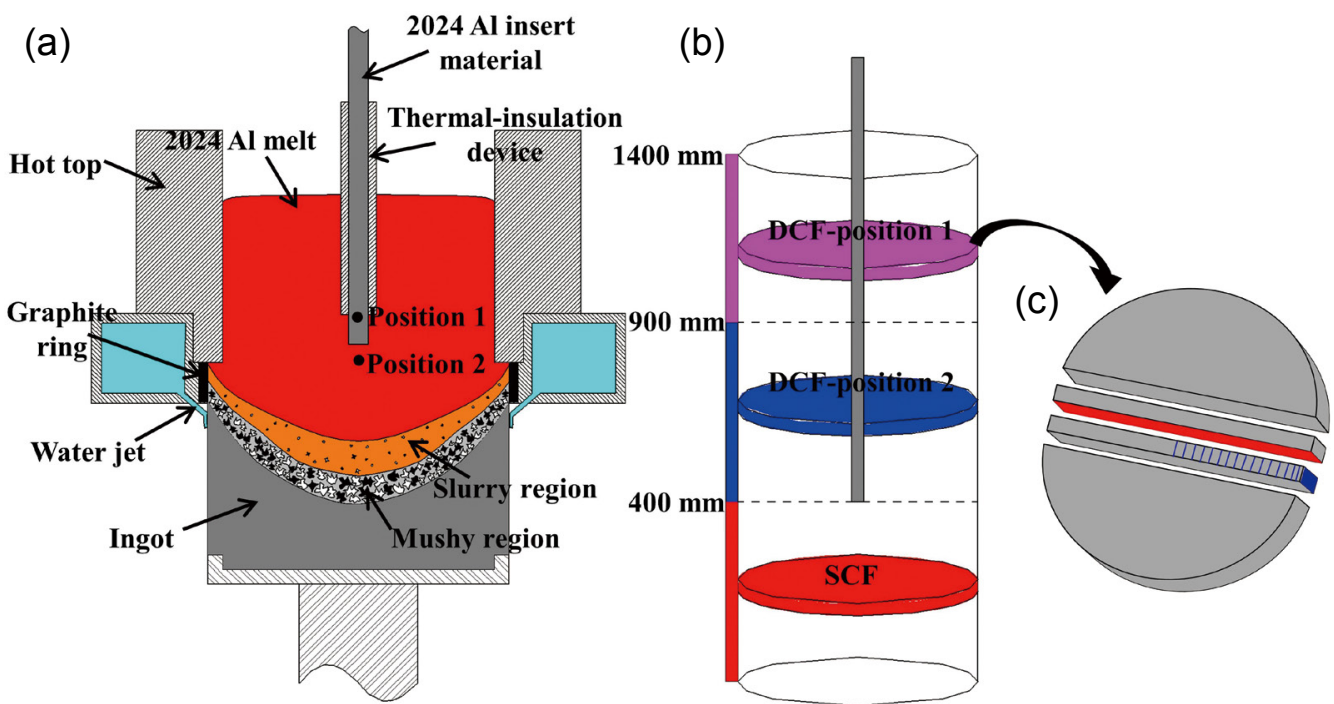

Fig. 2: Schematic view of DC casting process with DCF (a), and sampling positions for structure observation and composition testing $(b, c)$

Three transverse slices [Fig. 2(b)] were cut from the ingot processed with SCF or DCF, then, the slices were cut along the center plane. Samples for macro-corrosion [red area in Fig. 2(c)] were etched in $12 \mathrm{wt} . \% \mathrm{NaOH}$ water solution. A Sony A6000 digital camera was used to capture an image of the macrostructure. Samples for microstructure observation were cut along the radial direction of slices. These samples were polished using diamond suspensions and anodized under $20 \mathrm{~V}$ DC in 2.5wt.\% $\mathrm{HBF}_{4}$ water solution. An OLYMPUS-DX23 optical microscope (OM) was used to observe the microstructure. The average grain size was measured according to the standard of structure, as shown in Fig. 1(c).

A schematic view of the DC casting process of a $\Phi 300 \mathrm{~mm}$ $2024 \mathrm{Al}$ ingot is shown in Fig. 2(a), and the OM image of the ingot is shown in Fig. 1(b). First, the 2024 aluminum alloy was melted in the resistance furnace followed by degassing, stirring, and slag removing. When the temperature of the melt stabilized at $730{ }^{\circ} \mathrm{C}$, the melt was poured into the crystallizer. Then, the melt was cast at a speed of $65 \mathrm{~mm} \cdot \mathrm{min}^{-1}$ under a cooling water flow rate of $150 \mathrm{~L} \cdot \mathrm{min}^{-1}$. The casting process was performed in the same way as traditional DC casting. Then, the $2024 \mathrm{Al}$ rod, with the protection of a thermal-insulation device, was lowered to Position 1 or 2 [Fig. 2(a)], the thermal-insulation device was fixed, and the rod was gradually inserted into the molten pool along the central axis of the hot-top. The cylindrical thermalinsulation device was used to prevent the rod from contacting the melt in the upper part of the hot-top. The feeding speed of the rod was $150 \mathrm{~mm} \cdot \mathrm{min}^{-1}$. As shown in Fig. 2(a), Position 1 is on the central axis of the ingot and $50 \mathrm{~mm}$ above the upper edge of the graphite ring, and Position 2 is on the same level as the upper edge of the graphite ring. With the upper surface of the hot-top serving as the reference plane, two marking lines were cut on the outer surface of the thermal-insulation device according to the vertical distances between Position 1 or 2 and the upper surface of the hot-top, thus ensuring the thermalinsulation device can be actually lowered to Position 1 or 2 .
ASTM E112-96, using the linear intercept method. A ZEISS Ultra Plus scanning electron microscope (SEM) equipped with an energy dispersive spectroscope (EDS) was used to analyze the solute content inside different grains. In addition, a FoundryMaster Pro spark optical emission spectroscope (OES) was used to analyze the macrosegregation of $\mathrm{Cu}$ and $\mathrm{Mg}$ elements along the radial direction of the ingots. Sixteen samples from each casting condition were cut, as indicated by the blue lines in Fig. 2(c). Then, composition testing was performed at the flank of the samples [blue area in Fig. 2(c)]. Macrosegregation of $\mathrm{Cu}$ and $\mathrm{Mg}$ is characterized using an index $\Delta C$ (relative deviation), 
$\Delta C=\left(C_{i}-C_{0}\right) / C_{0}{ }^{[3]}$, where $C_{i}$ represents the average $\mathrm{Cu}$ or $\mathrm{Mg}$ content at one test position and $C_{0}$ represents the average $\mathrm{Cu}$ or $\mathrm{Mg}$ content of the ingot.

\section{Results}

\subsection{Structures}

Figure 3 exhibits the macrostructures of the ingots prepared by DC casting with SCF or DCF. For the ingot cast with SCF, the macrostructure consists of solidified shell near ingot surface, an area with feathery grains next to the shell, and coarse equiaxed grains in the region of the ingot center. For the ingots cast with DCF (with the insertion of $2024 \mathrm{Al}$ rod at Position 1), an area of about $70 \mathrm{~mm}$ in width with fine equiaxed grains can be observed in the center [dashed red rectangle in Fig. 3(b)] With lowering the inserting position to Position 2, marked by the dashed red rectangle in Fig. 3(c), the rod is agglomerated in the center region of the ingot, and a 10-20 mm wide transition zone [marked by the dashed red ellipse in Fig. 3(c)] can be observed between the insertion and the ingot. The results show that the insertion of the $2024 \mathrm{Al}$ rod does not significantly affect the solidified shell and the feathery grains zone but significantly refined the coarse equiaxed grains zone when the rod is inserted from Position 1.

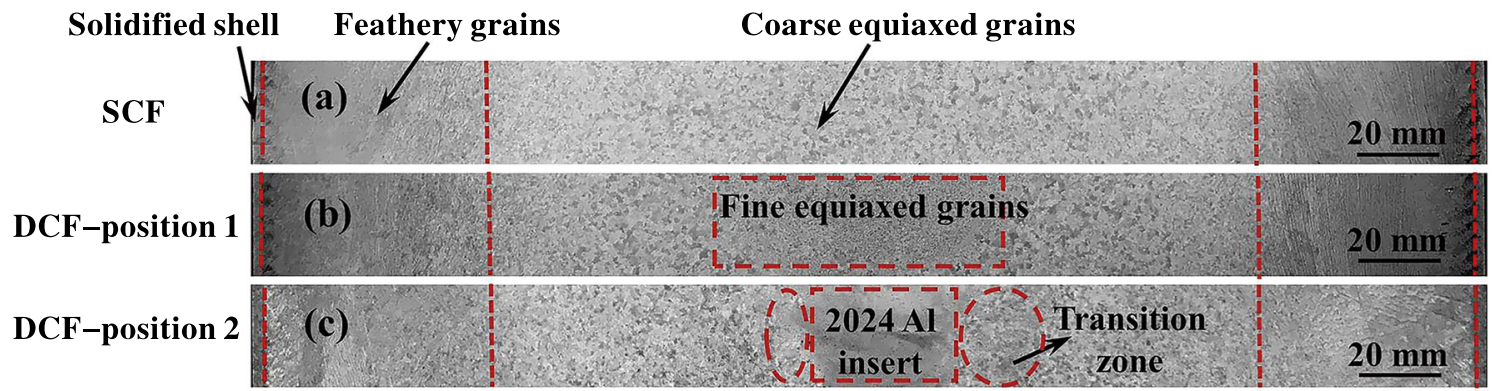

Fig. 3: Macrostructures of ingots with $\operatorname{SCF}(a)$ and DCF (b, c)

Figure 4 shows the microstructures of different ingots within a $1 / 3$ radius $(50 \mathrm{~mm})$ to the center. As shown in Fig. 4(a), the microstructure of the ingot cast with SCF mainly consists of coarse equiaxed grains. In addition, typical floating grains [marked by black dashed irregular graphic in Fig. 4(d)] with coarse-cell dendrites in the interior [marked by yellow dashed irregular graphic] and fine-cell dendrites in the periphery are observed in the center region of the ingot. For the ingot cast with DCF (with the insertion of $2024 \mathrm{Al}$ rod at Position 1), interestingly, grains [marked by the black dashed ellipse in Fig. 4(e)], which have large non-dendritic areas in the interior, are found in the fine equiaxed grains zone. With the insertion of $2024 \mathrm{Al}$ rod at Position 2, a good metallurgical interface is formed between the insertion and the ingot, as shown in Fig. 4(c). Moreover, the spherical grains in the $2024 \mathrm{Al}$ alloy insertion show a typical semi-solid structure ${ }^{[19-20]}$. In addition,

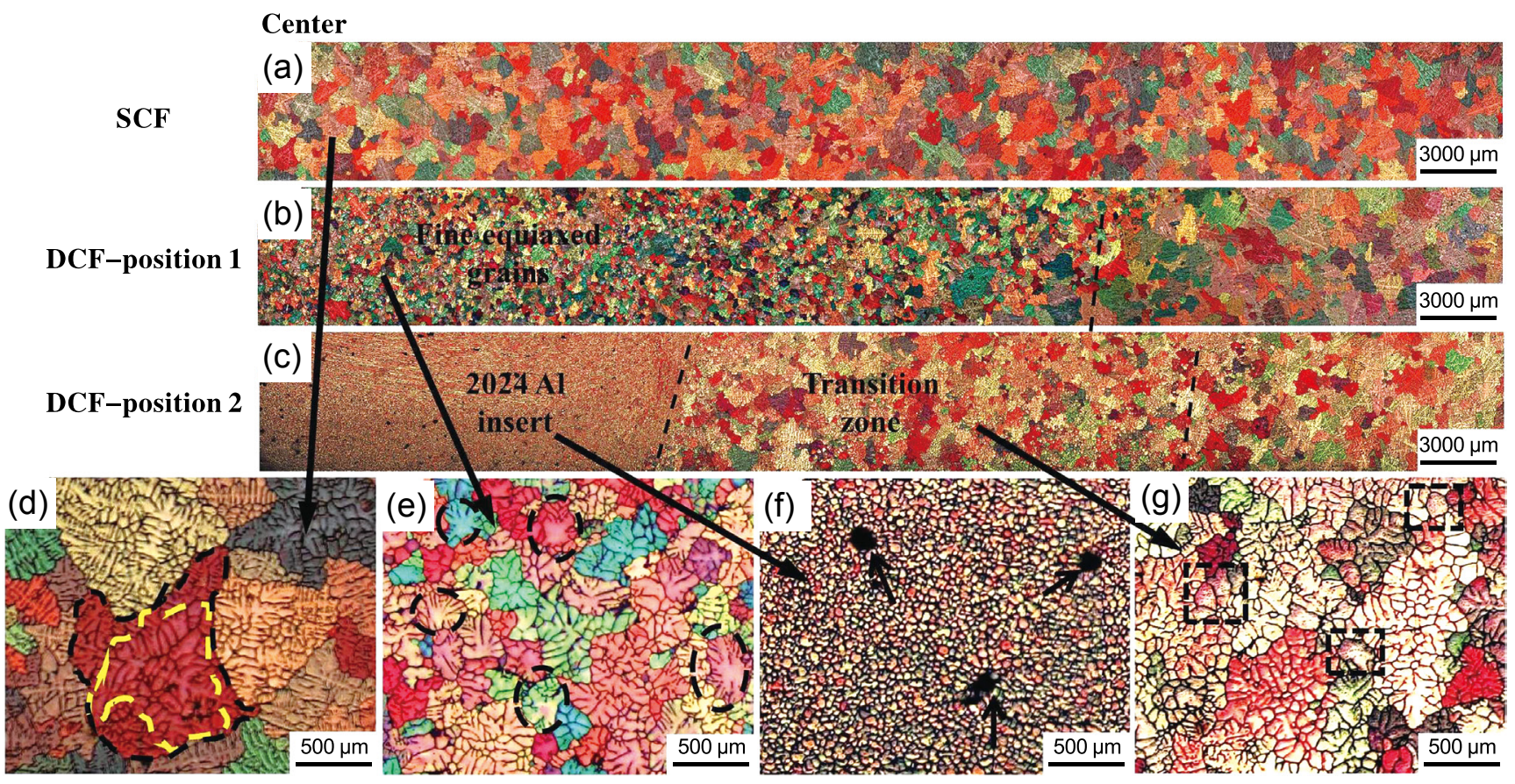

Fig. 4: OM images at center area of ingots with $\operatorname{SCF}(a, d)$ or DCF $(b, c, e-g)$ 
a large number of pores are found in the insertion [marked by the black arrows in Fig. 4(f)]. Finally, a mixed structure consisted of fine non-dendritic grains [marked by the dashed black rectangle in Fig. 4(g)] and coarse dendritic grains can be observed in the transition zone.

Figure 5 shows the microstructures at the positions of $75 \mathrm{~mm}$, $95 \mathrm{~mm}$, and $125 \mathrm{~mm}$ from the center of ingots. There is no difference of microstructure between the ingots cast with SCF and DCF in the range of 75-125 $\mathrm{mm}$ from the center of ingots. Moreover, feathery grains can be found in the outer region of the ingots. Thus, the microstructures in Fig. 4 and Fig. 5 indicate that the insertion of the $2024 \mathrm{Al}$ rods mainly affects the center region of ingots.
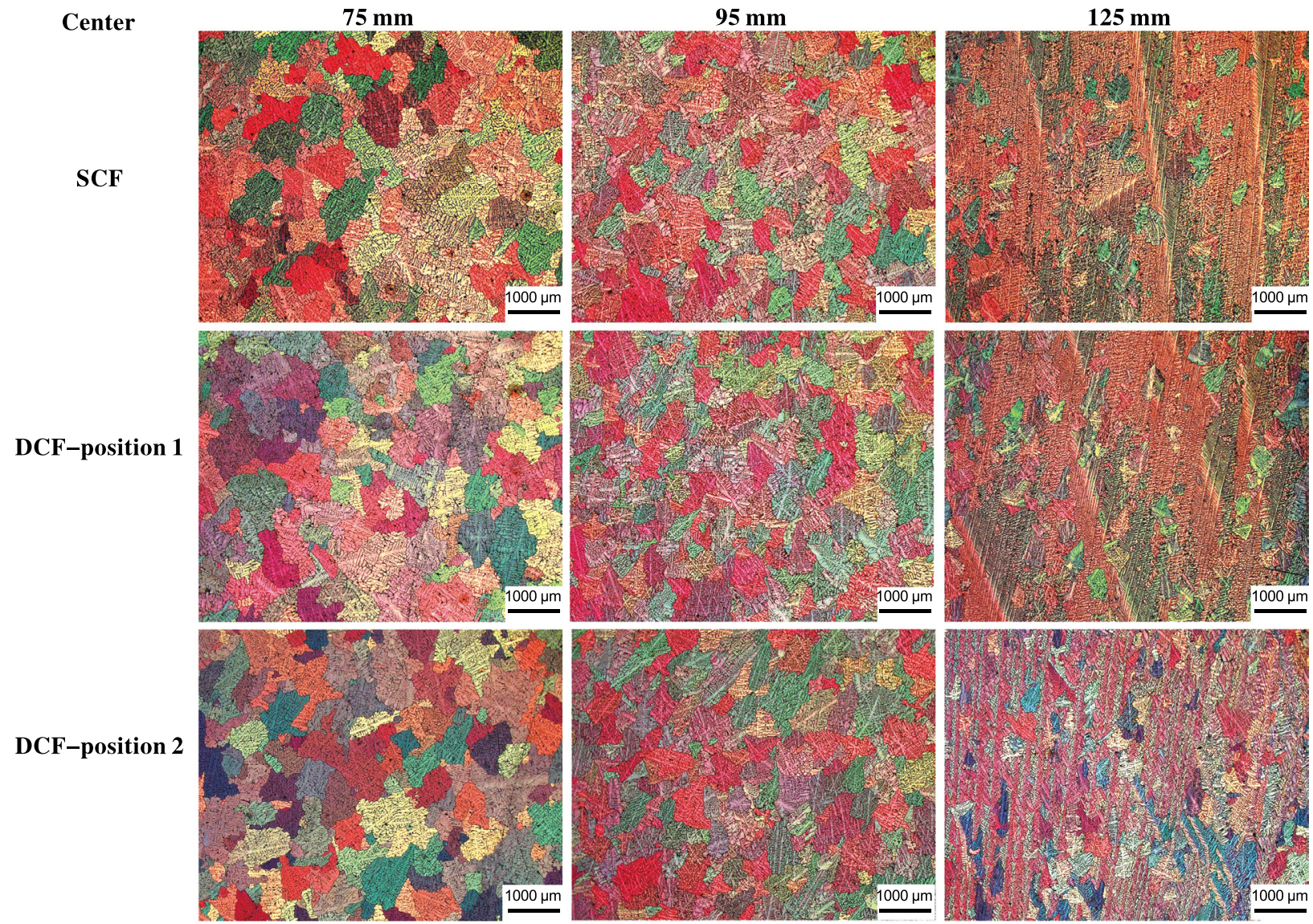

Fig. 5: OM images at different positions of ingots with SCF or DCF

Figure 6 shows the average grain size distribution of equiaxed grains from the center to the surface of the different ingots. With the insertion of $2024 \mathrm{Al}$ rod at Position 1, the average grain size in the center of the ingot cast with DCF is $369-488 \mu \mathrm{m}$, at the distance of $0-25 \mathrm{~mm}$ from the center of ingot, which is about $50 \%$ smaller than that of the ingot cast with SCF (891-896 $\mu \mathrm{m})$. With the insertion of $2024 \mathrm{Al}$ rod at Position 2, the average grain size is the smallest of the three ingots due to the fine spherical grains in the center. Moreover, the fine non-dendritic grains result in a decrease in the average grain size of the transition zone. Hence, at $25 \mathrm{~mm}$ from the center of the ingot, the average grain size with the $2024 \mathrm{Al}$ rod inserted at Position 2 is also smaller than that of the ingot without the insertion. However, at $50 \mathrm{~mm}, 75 \mathrm{~mm}$, and $95 \mathrm{~mm}$ from the center of the ingot, the average grain size does not change much with the application of DCF.

Figure 7 shows the SEM images and area scan spectrum maps of the samples taken from different points of the ingots cast with SCF or DCF. Several typical grains can be observed in

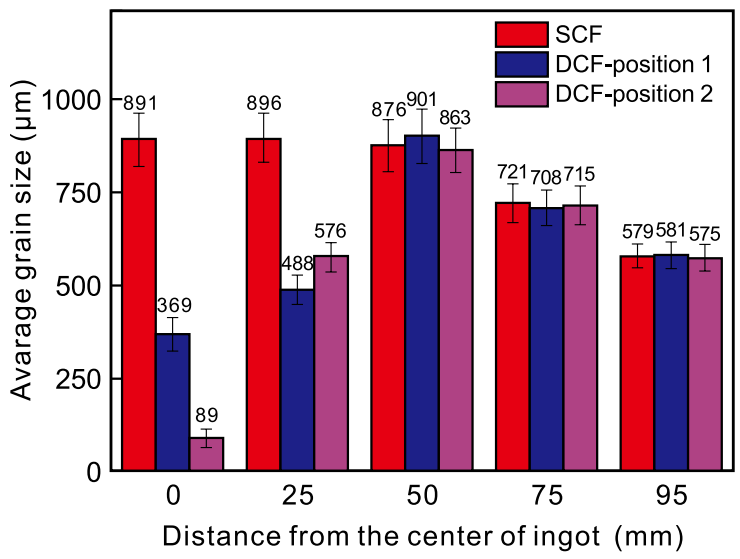

Fig. 6: Average grain size at different positions of ingots cast with SCF or DCF

each of the SEM images as being the same as those in the OM images (Fig. 4). The typical coarse-cell structures of floating grains are marked by the dashed black rectangle in Fig. 7(a). The grains with large non-dendritic areas in the interior are 


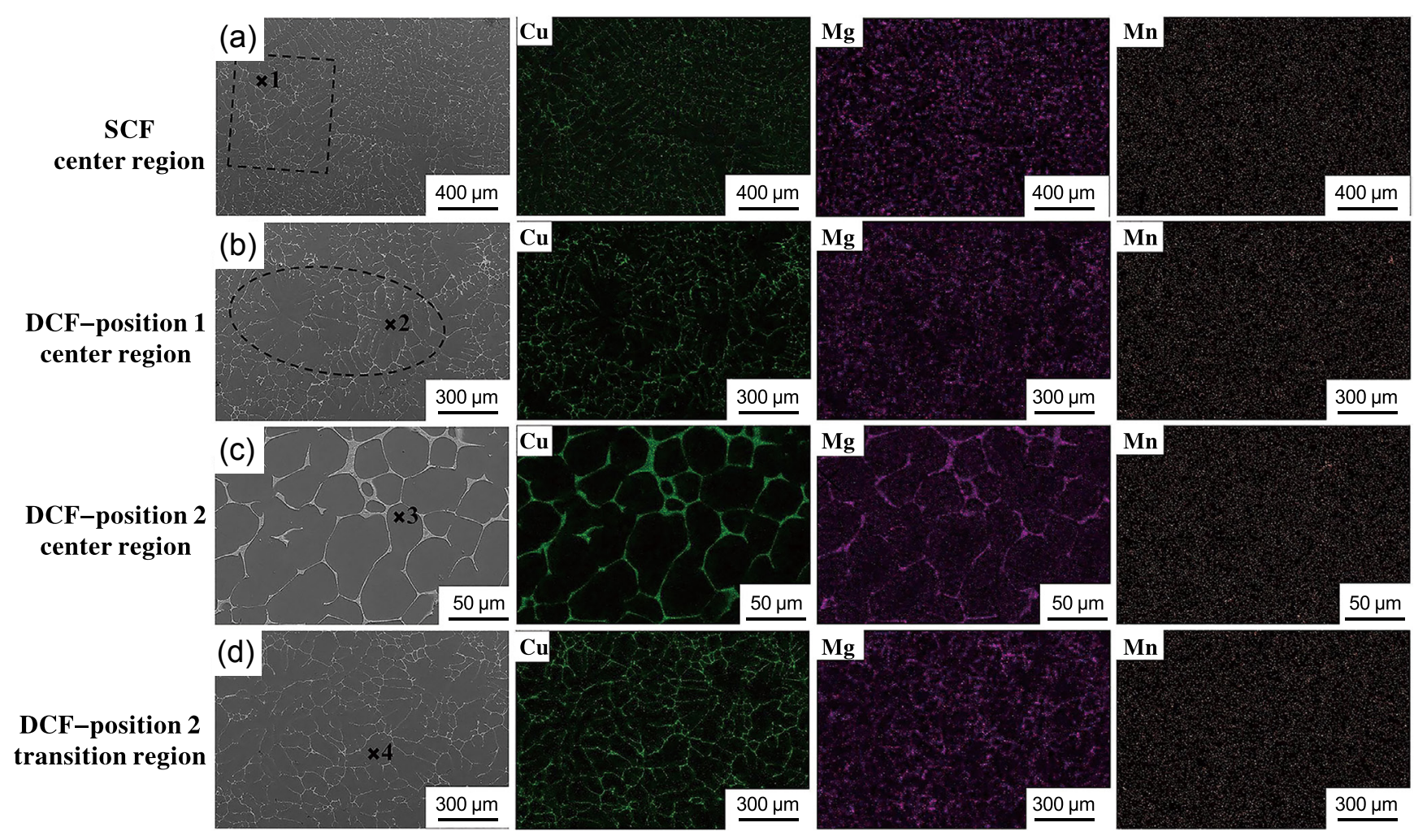

Fig. 7: SEM images and area scan spectrum maps of different samples taken from ingots cast with SCF (a) or $\operatorname{DCF}(b, c, d)$

marked by the dashed black ellipse in Fig. 7(b). The nearly spherical grains of the $2024 \mathrm{Al}$ insertion are shown in Fig. 7(c), and the equiaxed grains with coarse-cell structures are shown in Fig. 7(d). For all cases, $\mathrm{Cu}$ and $\mathrm{Mg}$ elements concentrate in the eutectic structure, inter dendritic arms or grain boundaries. However, the Mn element uniformly distributes within the grains. The points [marked by the black cross in Fig. 7(a-d)] at each typical grain were analyzed by using EDS through point scan spectrum (Table 1) to identify the differences in contents of solute elements between the different typical grains. As shown in Table 1, the content of Mn shows the most uniform distribution among the three elements. In addition, the $\mathrm{Cu}$ and Mg element contents are nearly the same between Points 1 and 4, and a similar result is also observed between Points 2 and 3 . However, the $\mathrm{Cu}$ and $\mathrm{Mg}$ element contents at Points 1 and 4 are much lower than those at Points 2 and 3 . The results mean that the coarse-cell structures of floating grains in the sample cast with SCF and the grains in the transition region of the ingot cast with DCF (Position 2) are confirmed to be solute-lean.

Table 1: Point scan spectrum results taken from different points as denoted by crosses in Fig. 7

\begin{tabular}{|cccc|}
\hline Points & $\mathrm{Cu}(\mathrm{wt} . \%)$ & $\mathrm{Mg}(\mathrm{wt} . \%)$ & $\mathrm{Mn}$ (wt.\%) \\
\hline Point 1 in Fig. 7(a) & 0.78 & 0.76 & 0.47 \\
Point 2 in Fig. 7(b) & 1.51 & 1.01 & 0.46 \\
Point 3 in Fig. 7(c) & 1.85 & 1.24 & 0.51 \\
Point 4 in Fig. 7(d) & 0.82 & 0.70 & 0.49 \\
\hline
\end{tabular}

However, the $\mathrm{Cu}$ and $\mathrm{Mg}$ contents in the spherical grains of the $2024 \mathrm{Al}$ insert and the special grains in the center of the ingot with DCF (Position 1) are closer to the nominal composition.

\subsection{Macrosegregation}

Figure 8 shows the macrosegregation of $\mathrm{Cu}$ and $\mathrm{Mg}$ elements along the radius of ingots. As shown in Fig. 8(a), within $20 \mathrm{~mm}$ from the center of the ingot, the relative deviation of the $\mathrm{Cu}$ element in the ingot with SCF is significantly greater than that in the ingots cast with DCF [marked by the dashed black ellipse in Fig. 8(a)]. At the center of the ingot cast with SCF, the relative deviation of $\mathrm{Cu}$ is -0.073 . For the ingot cast with DCF, the relative deviation of the $\mathrm{Cu}$ element is about 0.003 (with the insertion of $2024 \mathrm{Al}$ rod at Position 1) and 0.034 (with the insertion of $2024 \mathrm{Al}$ rod at Position 2). The results show a general negative centerline segregation region in the ingot prepared by traditional DC casting, and the negative centerline segregation of the $\mathrm{Cu}$ element can be decreased with the insertion of $2024 \mathrm{Al}$ rod. Within 20-40 mm from the center of the ingots, the relative deviation of $\mathrm{Cu}$ element is about -0.065 [marked by the dashed black rectangle in Fig. 8(a)] with the insertion of $2024 \mathrm{Al}$ rod at Position 2. This range corresponds to the transition region between unmolten insert and the ingot [Fig. 3(c)]. Hence, there is apparent negative segregation in the transition region. For all the cases, the relative deviation of the $\mathrm{Cu}$ element is relatively uniform in the range of $40-140 \mathrm{~mm}$, and is particularly high in the subsurface and surface region. As the relative deviation of $\mathrm{Cu}$ element in the subsurface region is less than zero and that in the surface region is greater than zero, there is strong negative segregation in the subsurface region 


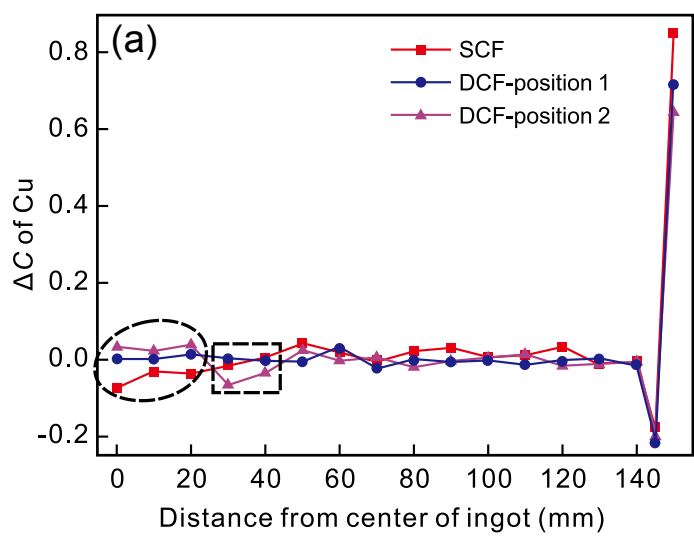

Fig. 8: Determined macrosegregation of $\mathrm{Cu}(\mathrm{a})$ and $\mathrm{Mg}(\mathrm{b})$

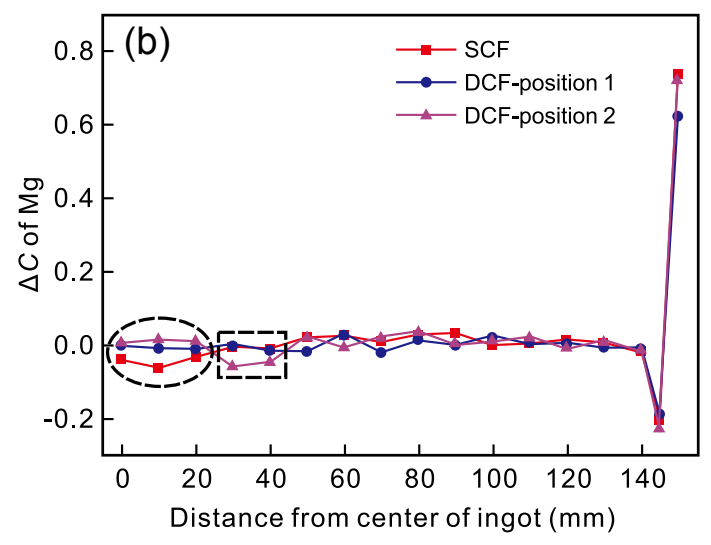

(b) at different points of ingots cast with SCF and DCF

of contact between the melt and insert differs, and so does the melt temperature around the insertion. As a result, some of the grains remelt in the moving process, and the unmolten grains become the source of equiaxed grains. These factors depend on the insertion positions of the $2024 \mathrm{Al}$ rods. Due to the heat transfer from the melt to the insert and from the insert to the cooled ingot, the insert melts from solid state to semi-solid or liquid state and resolidifies from semi-solid or liquid state into part of the ingot. A low melting degree of the insert will result in an obvious interface between the insert and the ingot. A high melting degree of the insert means the liquid phase of the insert mixes with the melt, and the unmolten $\alpha$-Al particles significantly influence the solidification structures. The melting degree of the insert is also affected by the inserting position.

Since the 2024 Al rod was inserted from Position 1, it went through a higher temperature region and was heated for a longer time. Therefore, most grains originating from the surface of the insert remelted in the sump. Moreover, a higher melting degree of the insert was achieved, resulting in a highvolume fraction of the liquid phase and a large number of nondendritic and nearly spherical $\alpha$-Al particles. The solid $\alpha$-Al particles act as the nucleus of heterogeneous nucleation, which make contributions to the increase in the number of nuclei and the refining of grains. In addition, these $\alpha-\mathrm{Al}$ particles are the source of the special grains in Fig. 4(e). Insertion at Position 2 is $50 \mathrm{~mm}$ below Position 1 and is closer to the bottom of the sump, which means that the melt temperature is lower, the distance to the solidified ingot is shorter, and the heating time is shorter. Hence, when the $2024 \mathrm{Al}$ rod was inserted from Position 2, lots of fine non-dendritic grains nucleated and separated from the surface region, part of which settled to the solidification front without much growth, and the others acted as the source of equiaxed grains in the transition region. In addition, the melting degree of the insert was lower. The structure of the $2024 \mathrm{Al}$ rod was changed from primary fibrous structure to non-dendritic and spheroidal structure after the inserting process, which was the typical structure of semisolid $2024 \mathrm{Al}$ alloys. In this state, as a small-volume fraction of liquid phase located at the boundary of $\alpha$-Al phase, the semisolid state of the insert had good liquidity and agglomerated in the center of the ingot. 


\subsection{Effect of double cooling field on macrosegregation}

Macrosegregation is a common defect in ingots prepared with DC casting. Generally, the surface layer of the ingot is removed, which means that the strong positive segregation in the surface and negative segregation in the subsurface have less effect on the application of ingots. However, the negative centerline segregation of the ingots cannot be eliminated, which seriously influences the composition uniformity of the ingots.

With conventional DC casting, the centerline segregation is mainly affected by thermal convection, floating grains, and the horizontal component of shrinkage-induced flow. The first causes positive (normal) centerline segregation, and the latter two contribute to negative centerline segregation ${ }^{\text {[24-27]. }}$. Generally, the effects of floating grains and shrinkage-induced flow play the dominant role in the segregation, which cause the negative centerline segregation of ingots. As for DC casting with DCF, when the $2024 \mathrm{Al}$ rod is inserted from Position 1, the solute content of the $\mathrm{Cu}$ and $\mathrm{Mg}$ elements in the unmolten particles from the $2024 \mathrm{Al}$ rods is higher than that in the floating grains and closer to the nominal composition, which is beneficial for reducing negative segregation. Due to the latent heat from the fusion of the insert, the isotherms in the center of the mushy zone could resemble a hillock-shape or become flatter. If the isotherm resembles a hillock-shape, the horizontal component of shrinkage flow is towards the center of the ingot, which is contrary to the horizontal component of shrinkage flow in traditional DC casting. If the isotherm becomes flatter, the horizontal component of shrinkage flow will be smaller. Therefore, with the application of DCF, the intensity of the horizontal component of shrinkage flow in the center region is decreased no matter whether the isotherm becomes hillockshaped or flatter. Overall, the negative centerline segregation is reduced when the $2024 \mathrm{Al}$ rod is inserted from Position 1. As the insertion position drops from Position 1 to Position 2, the grains in the transition region form earlier than the grains in the equiaxed grains region. Since the distribution coefficients of $\mathrm{Cu}$ and $\mathrm{Mg}$ elements are less than unity ${ }^{[21,25]}$, the concentrations of these elements in the solid phase are lower than that in liquid during the solidification process. Thus, the grains in the transition region are solute-poor, which causes the negative segregation in the transition region.

\section{Conclusions}

The effects of DCF on the structures and macrosegregation of a $2024 \mathrm{Al}$ ingot were studied, and the main conclusions are as follows:

(1) Introducing a $2024 \mathrm{Al}$ alloy rod into a melt of the same alloy during the DC casting process significantly refines the grains and reduces the negative centerline segregation, which is related to the inserting position of the rod.

(2) When inserted from Position 1 (50 mm above the uppper edge of the graphite ring), the $2024 \mathrm{Al}$ rod is fully melted, which consists of a high-volume fraction of liquid phase and a large number of unmolten $\alpha$-Al particles. As the $\alpha$-Al particles act as the nucleus of heterogeneous nucleation and increase the number of nuclei, the average grain size in the center region of the 2024 $\mathrm{Al}$ ingot cast with DCF is decreased by about $50 \%$, compared with that of the ingot cast with SCF. Meanwhile, the $\alpha$-Al particles originating from the insert are relatively solute-rich, which can reduce the negative centerline segregation of $\mathrm{Cu}$ and $\mathrm{Mg}$.

(3) When inserted from Position 2 (on the same level as the upper edge of the graphite ring), most of the $2024 \mathrm{Al}$ rod cannot be melted and the unmolten particles agglomerate in the center of the ingot, the microstructure of the unmolten rod is transformed from primary fibrous structure into nondendritic and spheroidal structure. However, the insert in the center region of the ingot, and the transition zone between the insert and the ingot lead to inhomogeneity in composition and structure.

\section{Acknowledgements}

This work was financially supported by the Natural Science Foundation of Liaoning Province (Nos. 2019-ZD-0002, 2019KF-0503), the Fundamental Research Funds for the Central Universities (Nos. N2002025, N2109006), and the National Natural Science Foundation of China (No. 51674078).

\section{References}

[1] Li R Q, Liu Z L, Dong F, et al. Grain refinement of a largescale Al alloy casting by introducing the multiple ultrasonic generators during solidification. Metallurgical and Materials Transactions A, 2016, 47: 3790-3796.

[2] Suyitno, Eskin D G, Katgerman L. Structure observations related to hot tearing of $\mathrm{Al}-\mathrm{Cu}$ billets produced by direct-chil casting. Materials Science and Engineering A, 2006, 420: 1-7.

[3] Eskin D G, Zuidema J, Savran V I, et al. Structure formation and macrosegregation under different process conditions during DC casting. Materials Science and Engineering A, 2004, 384: 232-244.

[4] Wang $\mathrm{H} \mathrm{J}, \mathrm{Xu} \mathrm{J}$, Kang $Y$ L, et al. Study on inhomogeneous characteristics and optimize homogenization treatment parameter for large size DC ingots of Al-Zn-Mg-Cu alloys. Journal of Alloys and Compounds, 2014, 585: 19-24.

[5] Gazanion F, Chen X G, Dupuis C. Studies on the sedimentation and agglomeration behavior of $\mathrm{Al}-\mathrm{Ti}-\mathrm{B}$ and $\mathrm{Al}-\mathrm{Ti}-\mathrm{C}$ grain refiners. Materials Science Forum, 2002, 396-402(1): 45-52.

[6] Limmaneevichitr $\mathrm{C}$, Eidhed H. Fading mechanism of grain refinement of aluminum-silicon alloy with Al-Ti-B grain refiners. Materials Science and Engineering A, 2003, 349: 197-206.

[7] Liu X D, Zhu Q F, Zuo Y B, et al. Effect of the intensity of melt shearing on the as cast structure of direct chill cast 2024 aluminum alloy. Metallurgical and Materials Transactions A, 2019, 50: 5727-5733

[8] Zuo Y B, Fan Z Y, Cui J Z. Grain refinement of AZ91D alloy by intensive melt shearing and its persistence after remelting and isothermal holding. China Foundry, 2013, 10(1): 39-42.

[9] Zhang L, Li X Q, Li R Q, et al. Effects of high-intensity ultrasound on the microstructures and mechanical properties of ultra-large $2219 \mathrm{Al}$ alloy ingot. Materials Science and Engineering A, 2019, 763: 138154. 
[10] Tang M O, Xu J, Zhang Z F, et al. Effects of annulus gap on flow and temperature field in electromagnetic direct chill casting process. Transactions of Nonferrous Metals Society of China, 2011, 21(5): 1123-1129.

[11] Luo Y J, Zhang Z F, Li B, et al. Effects of annular electromagnetic stirring coupled with intercooling on grain refinement and homogeneity during direct chill casting of large-sized 7005 alloy billet. JOM, 2017, 69(12): 2640-2643.

[12] Luo Y J, Zhang Z F. Numerical modeling of annular electromagnetic stirring with intercooling in direct chill casting of 7005 aluminum alloy billet. Progress in Natural Science: Materials International, 2019, 29: 81-87.

[13] He Y D, Yang Z Q. A casting method for copper and copper alloy ingots. China Patent, CN 102658359 A, 2012.

[14] Liu T, Wang Q D, Sun Y D, et al. Microstructure and mechanical properties of overcast $6101-6101$ wrought Al alloy joint by squeeze casting. Journal of Materials Science and Technology, 2016, 32: 298-304.

[15] Liu T, Wang Q D, Sun Y D, et al. An investigation into aluminumaluminum bimetal fabrication by squeeze casting. Materials and Design, 2015, 68: 8-17.

[16] Zhao K N, Liu J C, Nie X Y, et al. Interface formation in magnesium-magnesium bimetal composites fabricated by insert molding method. Materials and Design, 2016, 91: 122-131.

[17] Zhu C, Zhao Z H, Wang G S, et al. Effect of 2024 Al alloy insert on the grain refinement of a $2024 \mathrm{Al}$ alloy prepared via insert mold casting. Metals, 2019, 9: 1126-1135.

[18] Eskin D G, Wang F. Joint effect of ultrasonic vibrations and solid metal addition on the grain refinement of an aluminum alloy. Metals, 2019, 9: 161-168.
[19] Wang S C, Li Y Y, Chen W P, et al. Microstructure evolution of semi-solid 2024 alloy during two-step reheating process. Transactions of Nonferrous Metals Society of China, 2008, 18(4): 784-788.

[20] Atkinson H V, Burke K, Vaneetveld G. Recrystallisation in the semi-solid state in 7075 aluminium alloy. Materials Science and Engineering A, 2008, 490: 266-276.

[21] Eskin D G. Physical metallurgy of direct chill casting of aluminum alloys. Boca Raton: CRC Press, 2008: 428-441.

[22] Anada H, Tada S, Koshimoto K, et al. Effect of solidifying conditions on the spacing and inclining angle of twin boundaries of feathery crystals in Al-Mg alloys. Journal of Japan Institute Light Metals, 1991, 41(8): 497-503.

[23] Turchin A N, Zuijderwijk M, Pool J, et al. Feathery grain growth during solidification under forced flow conditions. Acta Materialia, 2007, 55: 3795-3801.

[24] Nadella R, Eskin D G, Du Q, et al. Macrosegregation in directchill casting of aluminum alloys. Progress in Materials Science, 2008, 53: 421-480.

[25] Eskin D G, Nadella R, Katgerman L. Effect of different grain structures on centerline macrosegregation during direct-chill casting. Acta Materialia, 2008, 56: 1358-1365.

[26] Eskin D G, Dua Q, Katgerman L. Relationship between shrinkage-induced macrosegregation and the sump profile upon direct-chill casting. Scripta Materialia, 2006, 55: 715-718.

[27] Vreeman C J, Incropera F P. The effect of free-floating dendrites and convection on macrosegregation in direct chill cast aluminum alloys Part II: predictions for $\mathrm{Al}-\mathrm{Cu}$ and $\mathrm{Al}-\mathrm{Mg}$ alloys. International Journal of Heat and Mass Transfer, 2000, 43(5): 687-704. 